\title{
Energy Shortage in Human and Mouse Models of SLC4A11-Associated Corneal Endothelial Dystrophies
}

\author{
Wenlin Zhang, ${ }^{1}$ Ricardo Frausto, ${ }^{1}$ Doug D. Chung, ${ }^{1}$ Christopher G. Griffis, ${ }^{1}$ Liyo Kao, ${ }^{2}$ \\ Angela Chen, ${ }^{1}$ Rustam Azimov, ${ }^{2}$ Alapakkam P. Sampath, ${ }^{1}$ Ira Kurtz, ${ }^{2,3}$ and Anthony J. Aldave ${ }^{1}$ \\ ${ }^{1}$ Stein Eye Institute, University of California, Los Angeles, Los Angeles, California, United States \\ ${ }^{2}$ Division of Nephrology, David Geffen School of Medicine at UCLA, Los Angeles, California, United States \\ ${ }^{3}$ Brain Research Institute, University of California, Los Angeles, Los Angeles, California, United States
}

Correspondence: Anthony J. Aldave, Stein Eye Institute, UCLA, 200 Stein Plaza, Los Angeles, CA 90095, USA; aldave@jsei.ucla.edu.

Received: April 29, 2020

Accepted: June 20, 2020

Published: July 28, 2020

Citation: Zhang W, Frausto R, Chung DD, et al. Energy shortage in human and mouse models of

SLC4A11-Associated corneal

endothelial dystrophies. Invest

Ophthalmol Vis Sci. 2020;61(8):39.

https://doi.org/10.1167/iovs.61.8.39
Purpose. To elucidate the molecular events in solute carrier family 4 member 11 (SLC4A11)-deficient corneal endothelium that lead to the endothelial dysfunction that characterizes the dystrophies associated with SLC4A11 mutations, congenital hereditary endothelial dystrophy (CHED) and Fuchs endothelial corneal dystrophy 4.

METHods. Comparative transcriptomic analysis (CTA) was performed in primary human corneal endothelial cells (pHCEnC) and murine corneal endothelial cells (MCEnC) with normal and reduced levels of SLC4A11 (SLC4A11 KD pHCEnC) and Slc4a11 (Slc4a11 ${ }^{-/}$ MCEnC), respectively. Validation of differentially expressed genes was performed using immunofluorescence staining of CHED corneal endothelium, as well as western blot and quantitative PCR analysis of $S L C 4 A 11 \mathrm{KD}$ pHCEnC and $S l c 4 a 11^{-1-}$ MCEnC. Functional analyses were performed to investigate potential functional changes associated with the observed transcriptomic alterations.

REsults. CTA revealed inhibition of cell metabolism and ion transport function as well as mitochondrial dysfunction, leading to reduced adenosine triphosphate (ATP) production, in SLC4A11 KD pHCEnC and Slc $4 a 11^{-1-}$ MCEnC. Co-localization of SNARE protein STX17 with mitochondria marker COX4 was observed in CHED corneal endothelium, as was activation of AMPK-p53/ULK1 in both SLC4A11 KD pHCEnC and Slc4a11 ${ }^{-/}$MCEnC, providing additional evidence of mitochondrial dysfunction and mitophagy. Reduced $\mathrm{Na}^{+}$-dependent $\mathrm{HCO}_{3}{ }^{-}$transport activity and altered $\mathrm{NH}_{4} \mathrm{Cl}$-induced membrane potential changes were observed in Slc $4 a 11^{-/-}$MCEnC.

Conclusions. Reduced steady-state ATP levels and subsequent activation of the AMPK-p53 pathway provide a link between the metabolic functional deficit and transcriptome alterations, as well as evidence of insufficient ATP to maintain the $\mathrm{Na}^{+} / \mathrm{K}^{+}$ATPase corneal endothelial pump as the cause of the edema that characterizes SLC4A11associated corneal endothelial dystrophies.

Keywords: SLC4A11, mitochondria dysfunction, AMPK, corneal endothelium, congenital hereditary endothelial dystrophy

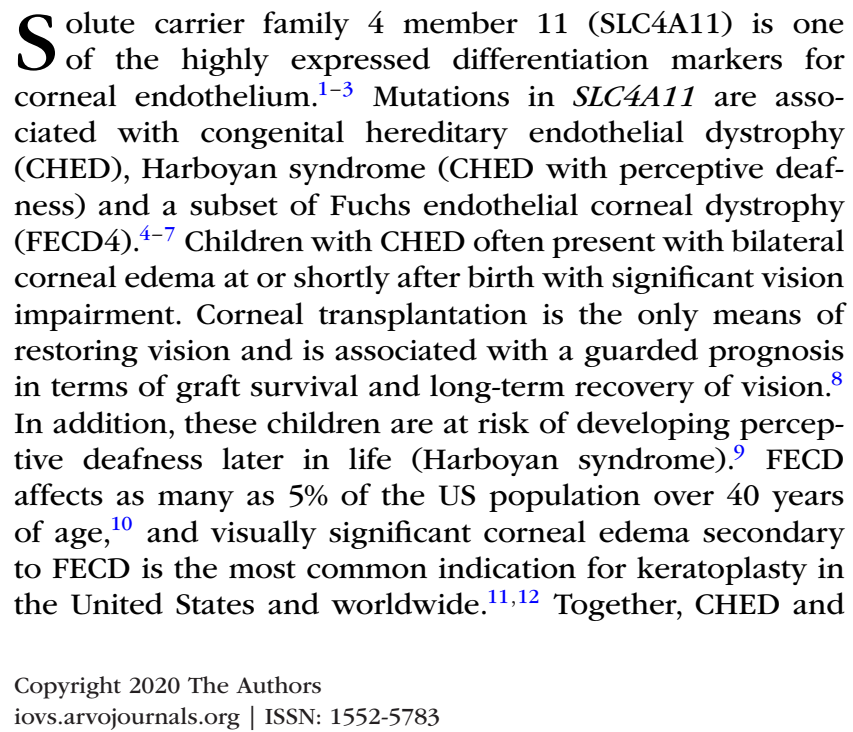

$\mathbf{S}$ olute carrier family 4 member 11 (SLC4A11) is one highly expressed differentiation markers for endothelium. ${ }^{1-3}$ Mutations in SLC4A11 are asso(CHED), Harboyan syndrome (CHED with perceptive deafness) and a subset of Fuchs endothelial corneal dystrophy (FECD4). ${ }^{4-7}$ Children with CHED often present with bilateral corneal edema at or shortly after birth with significant vision impairment. Corneal transplantation is the only means of restoring vision and is associated with a guarded prognosis in terms of graft survival and long-term recovery of vision. ${ }^{8}$ In addition, these children are at risk of developing perceptive deafness later in life (Harboyan syndrome). ${ }^{9}$ FECD affects as many as $5 \%$ of the US population over 40 years of age, ${ }^{10}$ and visually significant corneal edema secondary to FECD is the most common indication for keratoplasty in

FECD constitute common indications for corneal transplantation in published series from around the world. ${ }^{13,14}$

SLC4A11 is functionally characterized as an $\mathrm{NH}_{3}$ and alkaline pH-stimulated $\mathrm{H}^{+}$transporter, while permeability to $\mathrm{Na}^{+}, \mathrm{OH}^{-}$and water has also been reported. ${ }^{15-19}$ SLC4A11 is essential in facilitating energy-producing glutaminolysis, maintaining antioxidant signaling, and preventing apoptosis in corneal endothelial cells (CEnC). ${ }^{20-23}$ During development and in the event of oxidative DNA damage, SLC4A11 gene expression is upregulated by direct binding of phosphorylated (activated) p53. ${ }^{24}$ In SLC4A11-associated corneal endothelial dystrophies, the corneal edema that develops as a result of pathologic SLC4A11 mutations is evidence of CEnC dysfunction, either from direct cell loss/death or from disturbances in the CEnC "pump-leak" system. ${ }^{25-27}$ Corneal transparency is maintained by the CEnC "pump-leak" system through a dynamic balance between the passive leak of

This work is licensed under a Creative Commons Attribution-NonCommercial-NoDerivatives 4.0 International License. 
bioRxiv preprint doi: https://doi.org/10.1101/868281; this version posted August 13,2020 . The copyright holder for this preprint (which was not certified by peer review) is the author/funder. All rights reserved. No reuse allowed without permission.

Energy Shortage in SLC4A11 Deficient CEnC

aqueous humor fluid from the anterior chamber into the corneal stroma and the active pumping of fluid from the corneal stroma into the anterior chamber. The fluid pump activity is driven by an ionic electrochemical gradient set up by the highly expressed $\mathrm{Na}^{+} / \mathrm{K}^{+}$-ATPase. ${ }^{28}$ As such, CEnC have the second highest density of mitochondria among any cell types in the body (second to photoreceptors) to generate sufficient adenosine triphosphate (ATP) to fuel the $\mathrm{Na}^{+} / \mathrm{K}^{+}$ATPase-driven endothelial pump. ${ }^{29}$ As SLC4A11 plays a significant role in facilitating ATP-generating glutaminolysis in CEnC, ${ }^{22}$ it is not surprising that glutaminolysis inhibition, mitochondria membrane potential depolarization, enriched mitochondrial reactive oxidative species (ROS), and increased mitochondria turnover have been observed in the CEnC of the Slc $4 a 11^{-/-}$mouse..$^{22,23,30}$ Thus, the association between SLC4A11 and CEnC mitochondrial function suggests that SLC4A11 is involved not only in moving ions across the plasma membrane but also in the supply of energy to the endothelial pump.

Approximately 94 SLC4A11 mutations have been identified in individuals with CHED. ${ }^{4,6,9,31-48}$ Although a large number of these mutations result in SLC4A11 protein misfolding and failure to mature to the plasma membrane,, ,6,49-51 some mutations affect SLC4A11 transporter function without impacting membrane trafficking $^{17,52,53}$ or cause aberrant SLC4A11 pre-mRNA splicing and subsequent reduced SLC4A11 expression. ${ }^{47}$ Collectively, these observations support the hypothesis that loss of SLC4A11 function is the primary pathogenetic mechanism in CHED rather than mutant SLC4A11 protein misfolding/mislocalization in the endoplasmic reticulum (ER). Therefore, we investigated the impact of reduced SLC4A11 function on the CEnC transcriptome in primary human and murine immortalized $\mathrm{CEnC}$, with validation in corneal endothelium from individuals with CHED, and elucidated the upstream molecular mechanism leading to the observed transcriptomic changes.

\section{Materials ANd Methods}

\section{Primary Human Corneal Endothelial Cell Culture and Knockdown of SLC4A11}

Primary cultures of human corneal endothelial cells (pHCEnC) were established from donor corneas as previously described. ${ }^{54}$ After achieving a confluent monolayer, passage 1 of pHCEnC were transfected with $10 \mathrm{nM}$ antiSLC4A11 siRNA (CCGAAAGUACCUGAAGUUAAAGAACT) or scrambled siRNA (OriGene Technologies, Rockville, MD, USA) using Lipofectamine LTX (Life Technologies, Carlsbad, CA, USA). At 72 hours post-transfection, the cells were lysed for RNA, protein and ATP isolation.

\section{Immortalized Mouse Corneal Endothelial Cell Culture}

Immortalized $S l c 4 a 11^{+/+}$and $S l c 4 a 11^{-/-}$mouse corneal endothelial cell (MCEnC) lines were derived from Slc4a11 $1^{+/+}$ and $S l c 4 a 11^{-/-}$mice corneal endothelium and were cultured at $33^{\circ} \mathrm{C}$ in Opti-MEM I medium (Thermo Fisher Scientific, Waltham, MA, USA) with supplements as previously described. ${ }^{23}$ Passages 6 and 39 of Slc $4 a 11^{-1-}$ and passages 7 and 40 of $S l c 4 a 11^{+/+}$MCEnC were lysed for RNA isolation. Passages 10 and 44 of $S l c 4 a 11^{-/-}$and passages 11 and 45 of Slc $4 a 11^{+/+}$MCEnC were lysed for protein and ATP isolation.
IOVS | July 2020 | Vol. 61 | No. 8 | Article 39 | 2

\section{Total RNA Isolation from pHCEnC and MCEnC}

Total RNA from cultured pHCEnC was isolated in TRI Reagent and purified with the RNeasy Clean-Up Kit (Qiagen, Hilden, Germany). Total RNA from cultured MCEnC was isolated and purified using the Qiagen RNeasy Plus Mini Kit.

\section{RNA Sequencing of Total RNA from pHCEnC and MCEnC}

Purified total RNA from pHCEnC was prepared for RNA sequencing libraries using the KAPA mRNA HyperPrep Kit (Roche Sequencing Solutions, Pleasanton, CA, USA). Libraries were sequenced on the HiSeq 4000 (Illumina, San Diego, CA, USA), and paired-end 150-bp reads were generated. Purified total RNA from the MCEnC was submitted to the UCLA Technology Center for Genomics \& Bioinformatics for library preparation and sequencing. Single-end 50-bp reads were generated using the Illumina HiSeq 3000. The generated FASTQ files and quantitative results are available from the NCBI Gene Expression Omnibus database (accession numbers GSE142635 and GSE142636).

\section{RNA Sequencing Data Analyses}

Raw reads from pHCEnC and MCEnC samples were aligned to the human (GRCh38/hg38) and mouse (GRCm38/mm10) genomes, respectively, using HISAT2. Raw counts of aligned reads were converted to counts per million (CPM) mapped reads and normalized by the method of trimmed mean of M-values to adjust for library size differences. Linear models for microarray analysis coupled with variance modeling at the observation level were used for differential gene expression analysis. The CPM fold changes of gene transcripts were calculated by comparing each sample set to the appropriate control: (1) pHCEnC sample set, pHCEnC transfected with siRNA targeting $S L C 4 A 11$ (SLC4A11 KD pHCEnC, $n=3)$ versus pHCEnC transfected with scrambled RNA (scRNA pHCEnC, $n=3$ ); (2) MCEnC early sample set, Slc $4 a 11^{-/-}$MCEnC passage $6(n=4)$ versus Slc $4 a 11^{+/+}$ MCEnC passage $7(n=4)$; and (3) MCEnC late sample set, Slc $4 a 11^{-/-}$MCEnC passage $39(n=4)$ versus $S l c 4 a 11^{+/+}$ MCEnC passage $40(n=4)$. The following thresholds were applied to define genes with differential expression: CPM $>1$, fold change $>1$, and adjusted $P<0.05$. A differential gene expression (DGE) list was created for each of the three sample sets, after which comparative transcriptome analysis was performed by comparing the three DGE lists to identify common differentially expressed genes (DEG) and enriched pathways.

\section{Ingenuity Pathway Analysis}

Qiagen Ingenuity Pathway Analysis (IPA) was used to perform comparative transcriptome analysis among the three DGE lists (pHCEnC, MCEnC early, and MCEnC late), including canonical/biological function pathway enrichment and upstream regulator prediction analyses. Enriched canonical and biological function pathways with a predicted activation $z$-score in each of the three DGE lists were sorted by the sign and value of the $z$-score to identify the most enriched pathways. Enriched pathways without an assigned $z$-score and predicted upstream regulators were ranked by mean of enrichment $P$ values. 
bioRxiv preprint doi: https://doi.org/10.1101/868281; this version posted August 13,2020 . The copyright holder for this preprint (which was not certified by peer review) is the author/funder. All rights reserved. No reuse allowed without permission.

\section{Quantitative PCR}

Quantitative PCR (qPCR) was performed on separate batches of RNA samples isolated from passage 1 of $S L C 4 A 11 \mathrm{KD}$ and scRNA pHCEnC, as well as Slc4a11 ${ }^{-/-}$MCEnC passages 6 and 39 and of Slc4a11 $1^{+/+}$MCEnC passages 7 and 40 . Total RNA of each sample was reversed transcribed using the SuperScript III First-Strand Synthesis System (Sigma-Aldrich, St. Louis, MO, USA). Quantitative PCR was performed on the LightCycler 480 System (Roche, Basel, Switzerland) using Kapa SYBR Fast Universal Kit (Roche) with an annealing temperature of $60^{\circ} \mathrm{C}$ and with primers listed in Supplementary Table S1. Relative gene expression was calculated by the comparative $\mathrm{C}_{\mathrm{t}}\left(2^{-\Delta \mathrm{Ct}}\right)$ method in comparison to the housekeeping gene PPIA/Ppia or ACTB/Actb.

\section{Immunofluorescence}

Five-micrometer sections of paraffin-embedded corneas from seven healthy donors and two individuals with CHED were de-paraffinized and rehydrated in a graded ethanol series $(100 \%, 95 \%, 70 \%$ and $50 \%)$ for 5 minutes each and subject to antigen retrieval in $10 \mathrm{mM}$ sodium citrate. Sections were incubated with primary antibodies overnight at $4^{\circ} \mathrm{C}$ and with secondary antibodies for 1 hour (Supplementary Table S2). Sections were mounted with Invitrogen ProLong Antifade Mountant (Thermo Fisher Scientific) and imaged with an Olympus FV-1000 inverted confocal fluorescence microscope (Olympus Corporation, Tokyo, Japan). Florescence intensity of the images were quantified using Olympus FluoView 4.2 and ImageJ software (National Institutes of Health, Bethesda, MD, USA).

\section{Single Cell Patch-Clamp Recordings}

Single cell recordings were made from a single adhered MCEnC after culturing of MCEnC on 25-mm glass coverslips to $\sim 10 \%$ to $20 \%$ confluence. Membrane voltages were measured using whole-cell patch electrodes in current clamp mode $\left(\mathrm{I}_{\text {hold }}=0\right)$ as previously described. ${ }^{55}$ Data were reported as mean ( $95 \% \mathrm{CI}$ ). Details of the experimental setup and solutions used are provided in the Supplementary Materials.

\section{Intracellular pH Measurement}

Intracellular $\mathrm{pH}\left(\mathrm{pH}_{\mathrm{i}}\right)$ measurements were performed by monitoring intracellular free $\mathrm{H}^{+}$concentration using the $\mathrm{pH}-$ sensitive fluorescent dye BCECF-AM (B1170; Thermo Fisher Scientific) as described previously. ${ }^{19,20}$ Details of the experimental setup and solutions used are provided in the Supplementary Materials.

\section{Western Blotting}

Whole-cell lysates from pHCEnC and MCEnC were prepared with radioimmunoprecipitation assay buffer with proteinase and phosphatase inhibitors. Total protein was quantified by bicinchoninic acid (BCA) assay, separated and detected using the Simple Western assay Wes (ProteinSimple, San Jose, CA, USA). Quantification and data analysis were performed in Compass for Simple Western software (ProteinSimple). Antibodies used are listed in Supplementary Table S2.

\section{Intracellular ATP Assay}

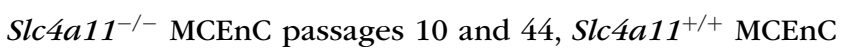
passages 11 and 45 and pHCEnC passage 1 were seeded at $1 \times 10^{5}$ cells $/ \mathrm{mL}$ in 12-well (MCEnC) and 24-well (pHCEnC) plates and cultured to subconfluence. SLC4A11 was knocked down in confluent pHCEnC with siRNA as described above. ATP was extracted by a boiling water method $^{56}$ and measured using a luciferin-luciferase ATP determination kit (Molecular Probes, Eugene, OR, USA).

\section{Human Corneal Endothelium from Individuals with CHED}

The authors followed the tenets of the Declaration of Helsinki in the treatment of the subjects reported herein. This study was approved by the Institutional Review Board at The University of California, Los Angeles (UCLA IRB \#11000020) and was performed after obtaining informed written consent from the parents of affected individuals with CHED who underwent penetrating keratoplasty.

\section{Statistical Analysis}

All $P$ values used in the transcriptomic analysis to identify gene differential expression and pathway enrichment were false discovery rate adjusted $P$ values. Statistical analysis, for data other than transcriptomes and patch-clamp recordings, was performed in Prism 7.0 (GraphPad, San Diego, CA, USA) with appropriate statistical tests based on the data structure. Specific statistical tests used for each comparison are indicated in figure legends. Data are presented as mean \pm SEM. Statistical significance is denoted as follows in the figures:

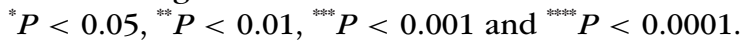

\section{Results}

\section{CHED Corneal Specimens Suggest That SLC4A11 Mutations Are Not Associated with Decreased Mutant SLC4A11 Expression}

Corneal specimens from two individuals with CHED were examined with light microscopy and immunohistochemistry. One of the two individuals $\left(S L C 4 A 11^{\mathrm{Mu} / \mathrm{Mu}}\right)$ demonstrated compound heterozygous mutations in SLC4A11 (NM_032034) (c. [473_480delGCTTCGCCinsC; 2623C >T], p.[R158PfsX3; Arg875*]) and the other (SLC4A11 $\left.{ }^{\mathrm{Mu} / \mathrm{WT}}\right)$ demonstrated a single heterozygous SLC4A11 coding region mutation (c.2146C $>$ G, p.Pro716Ala). Both corneal specimens demonstrated a significantly thickened Descemet membrane and an attenuated aberrant CEnC layer with cytoplasmic inclusions present in some cells (Fig. 1A). Immunofluorescence staining for SLC4A11 protein in the corneal endothelium was performed in conjunction with the use of an antibody against an ER marker, protein disulfide isomerase (PDI), to investigate whether these SLC4A11 mutations lead to protein misfolding and retention in the ER, as previously reported. 5,6,50 There was no apparent difference in SLC4A11 protein staining intensity between the two specimens from the individuals with CHED, in which the staining localized to the cellular membrane and did not colocalize with PDI, and seven healthy controls (Fig. 1B). 
bioRxiv preprint doi: https://doi.org/10.1101/868281; this version posted August 13,2020 . The copyright holder for this preprint (which was not certified by peer review) is the author/funder. All rights reserved. No reuse allowed without permission.

Energy Shortage in SLC4A11 Deficient CEnC IOVS | July 2020 | Vol. 61 | No. 8 | Article 39 | 4
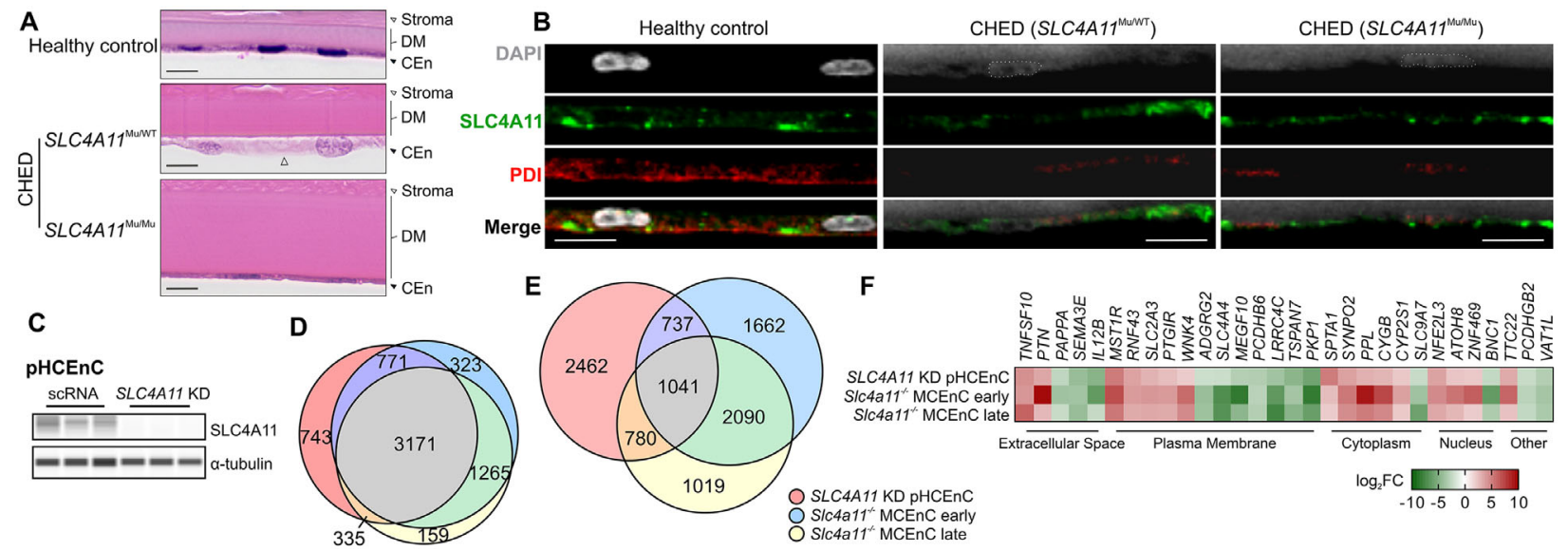

Figure 1. SLC4A11 deficiency leads to transcriptome alteration in corneal endothelium. (A) Histopathologic examination of control and CHED corneas demonstrating Descemet membrane (DM) thickening and corneal endothelial cell (CEnC) alteration or attenuation in corneas from individuals with CHED (H\&E stain). $\Delta$, cytoplasmic inclusion. Scale bar: $10 \mu \mathrm{m}$. (B) Representative images of immunofluorescence staining for SLC4A11 (green signal) and the ER marker PDI (red signal) in corneal endothelium of two individuals with CHED and healthy control. Nucleus were stained with 4',6-diamidino-2-phenylindole (DAPI; gray signal). Scale bar: $10 \mu \mathrm{m}$. (C) Western blot analysis for SLC4A11 in pHCEnC treated with siRNA against SLC4A11 (SLC4A11 KD) and scRNA for 72 hours. Each lane in the western blot represents an independent primary HCEnC culture established from a unique donor cornea. (D) Venn diagram of the endothelial transcriptome in SLC4A11 KD pHCEnC and Slc4a11-/- MCEnC early and late passages indicating the number of differentially expressed genes (DEG) in each of the sample sets. (E) Venn diagram of the endothelial transcriptome in SLC4A11 KD pHCEnC and Slc4a11 ${ }^{-1-}$ MCEnC early and late passages indicating the number of DEG in the same direction in each of the sample sets. (F) Heat map of top 30 most highly differentially expressed genes shared among SLC4A11 KD pHCEnC and Slc4a11 ${ }^{-1-}$ MCEnC early and late passages. Genes are clustered based on cellular localization of the gene product.

\section{SLC4A11/Slc4a11 Reduction Induces Corneal Endothelial Transcriptome Changes}

Next, to mimic the loss of SLC4A11 function in CHED, we knocked down SLC4A11 in pHCEnC (Fig. 1C) and utilized an immortalized MCEnC cell line from a $S l c 4 a 11^{-1-}$ mouse. We then performed transcriptomic analysis of pHCEnC and MCEnC with normal and reduced levels of SLC4A11 and Slc4a11, respectively. Based on the shared corneal endothelial phenotypes between individuals with CHED and the Slc $4 a 11^{-/-}$mouse, we compared the transcriptomes from SLC4A11 KD pHCEnC and early and late passage MCEnC derived from Slc4a11 ${ }^{-/-}$mice. ${ }^{23}$ Both early and late MCEnC passages were included in the analysis so that transcriptomic changes due to the loss of Slc4a11 could be differentiated from the transcriptomic changes introduced by prolonged culture. A comparison of the DEG identified from each sample set revealed 3171 genes that were consensually differentially expressed across three sample sets (Fig. 1D), of which 1041 genes were differentially expressed in the same direction (Fig. 1E). Over a third of the 30 most highly DEG (Fig. 1F) have been previously demonstrated to play important functional roles in the cornea and/or have been associated with corneal diseases, including SEMA3E, ${ }^{1} M S T 1 R,{ }^{57}$ RNF43, ${ }^{58}$ SLC $2 A 3,{ }^{2}$ WNK4, ${ }^{59}$ SLC $4 A 4,{ }^{26}$ CYGB, ${ }^{60} S L C 9 A 7,, 61$ ZNF469, ${ }^{62-65}$ BNC1 $^{66}$ and TTC22. ${ }^{67}$

\section{Loss of SLC4A11 Leads to Generalized Inhibition of Cellular Metabolism}

Comparison of enriched canonical pathways in Slc4a11 KD pHCEnC, Slc4a11-/- MCEnC early (passage 6) and Slc $4 a 11^{-1-}$ MCEnC late (passage 39) sample sets identified a shared generalized inhibition (defined by negative activation $z$-score) of multiple metabolic pathways that were intercon- nected via intermediate metabolites (Figs. 2A, 2B). A generalized decrease in the expression of enzyme-encoding genes in these pathways was observed (Figs. 2C-2I), a finding that was confirmed for selected genes from each pathway using qPCR (Fig. 2J).

\section{Altered Expression of Ion Channels and Transporters Impairs Transport Function of Corneal Endothelium}

IPA biological function enrichment analysis identified "transport of molecule" as the top inhibited function (negative $z$-score) shared between the transcriptomes of the pHCEnC, MCEnC early and MCEnC late samples sets (Fig. $3 \mathrm{~A})$. Because SLC4A11 is an electrogenic $\mathrm{NH}_{3}: \mathrm{H}^{+}$cotransporter, ${ }^{15}$ we performed single cell recordings of the membrane potential of Slc $4 a 11^{+/+}$and Slc $4 a 11^{-/-}$MCEnC, in which the resting membrane potential is not statistically different (Fig. 3B), in response to extracellularly perfused $10 \mathrm{mM} \mathrm{NH}_{4} \mathrm{Cl}$. Although exposure to $\mathrm{NH}_{4} \mathrm{Cl}$ induced a $+\mathbf{1 2 . 7}$ $\mathrm{mV}(95 \% \mathrm{CI},+5$ to $+20 \mathrm{mV})$ depolarization in $\mathrm{Slc} 4 \mathrm{a11} 1^{+/+}$ MCEnC, likely due to the $\mathrm{NH}_{3}: \mathrm{H}^{+}$permeability provided by Slc4a11, exposure to $\mathrm{NH}_{4} \mathrm{Cl}$ induced a $-9.50 \mathrm{mV}$ (95\% CI, -19.3 to $-0.5 \mathrm{mV}$ ) hyperpolarization in $\mathrm{Slc} 4 a 11^{-1-}$ MCEnC (Figs. 3C, 3D).

To investigate the nature of this depolarization to hyperpolarization shift resulting from loss of Slc4a11, we examined the list of 1041 genes differentially expressed in the same direction in the SLC4A11 KD pHCEnC, Slc $4 a 11^{-1-}$ MCEnC early and MCEnC late sample sets to identify ion channels and transporters. We identified 12 genes encoding ion channels and 26 genes encoding transporters were either upregulated or downregulated, including SLC4A11 (Fig. 3E, Table). The electrogenic $\mathrm{Na}^{+}-\mathrm{HCO}_{3}{ }^{-}$cotransporter 
bioRxiv preprint doi: https://doi.org/10.1101/868281; this version posted August 13, 2020. The copyright holder for this preprint (which was not certified by peer review) is the author/funder. All rights reserved. No reuse allowed without permission.
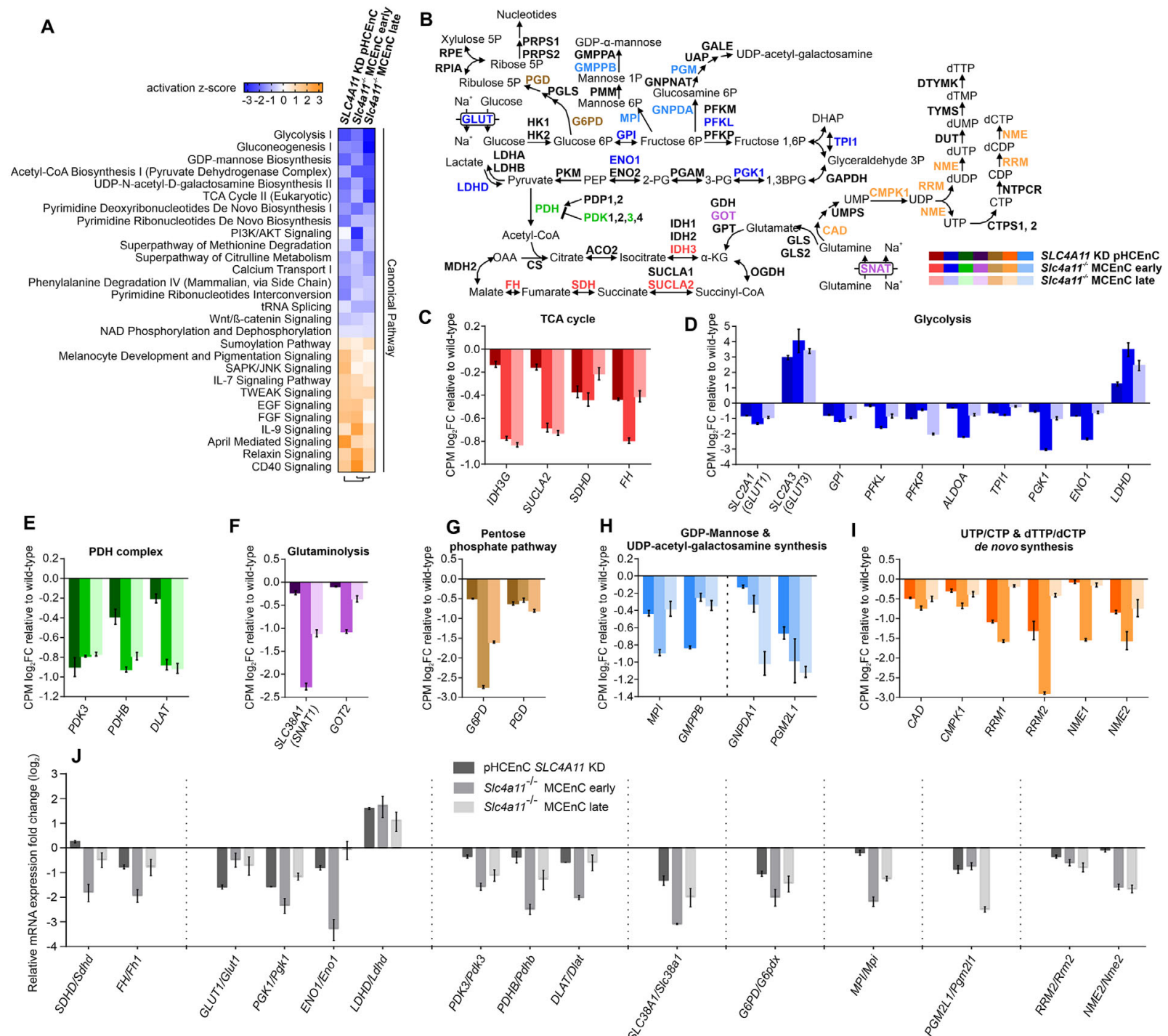

FIGURE 2. Inhibition of multiple metabolic pathways in SLC4A11-deficient corneal endothelial cells. (A) Heat map showing consensually enriched IPA canonical pathways from comparison of transcriptomes of $S L C 4 A 11 \mathrm{KD}$ pHCEnC and Slc4a11 ${ }^{-/}$MCEnC early and late passages (sorted by mean activation $z$-score). (B) Schematic illustration of the crosstalk among identified inhibited metabolic pathways. Differentially expressed genes encoding key enzymes are color coded using the same colors as used in $\mathbf{C}$ to $\mathbf{I}$. Shown are transcript levels of differentially expressed enzyme-coding genes involved in the following: (C) Citric acid cycle (tricarboxylic acid cycle, TCA). IDH3G, isocitrate dehydrogenase $3\left(\mathrm{NAD}^{+}\right)$gamma; SUCLA2, succinate-CoA ligase ADP-forming beta subunit; SDHD, succinate dehydrogenase complex subunit D; FH, fumarate hydratas. (D) Glycolysis. GLUT1/3, glucose transporter type 1 and 3; GPI, glucose-6-phosphate isomerase; PFKL, phosphofructokinase, liver type; PFKP, phosphofructokinase, platelet; $A L D O A$, aldolase, fructose-bisphosphate A; TPI1, triosephosphate isomerase 1; PGK1, phosphoglycerate kinase 1; ENO1, enolase 1; LDHD, lactate dehydrogenase. (E) Acetyl-CoA biosynthesis/pyruvate dehydrogenase (PDH) complex. PDK3, pyruvate dehydrogenase kinase 3; PDHB, pyruvate dehydrogenase E1 beta subunit; DLAT, dihydrolipoamide $S$ acetyltransferase. (F) Glutaminolysis. SNAT1, system N amino acid transporter 1; GOT2, glutamic-oxaloacetic transaminase 2. (G) Pentose phosphate shunt. G6PD, glucose-6-phosphate dehydrogenase; PGD, phosphogluconate dehydrogenase. (H) GDP-mannose synthesis. MPI, mannose phosphate isomerase; GMPPB, GDP-mannose pyrophosphorylase B in UDP-acetyl-galactosamine synthesis; GNPDA1, glucosamine6-phosphate deaminase 1; PGM2L1, phosphoglucomutase 2 like 1. (I) Pyrimidine ribonucleotide (UTP/CTP) and pyrimidine deoxyribonucleotide (dTTP/dCTP) de novo synthesis. CAD, carbamoyl-phosphate synthetase 2, aspartate transcarbamylase, and dihydroorotase; CMPK1, cytidine/uridine monophosphate kinase 1; RRM1, ribonucleotide reductase catalytic subunit M1; RRM2, ribonucleotide reductase regulatory subunit M2; NME1, NME/NM23 nucleoside diphosphate kinase 1; NME2, NME/NM23 nucleoside diphosphate kinase 2. (J) Selected differentially expressed genes from each pathway listed above were validated by qPCR in separate RNA isolations from SLC4A11 KD pHCEnC and Slc4a11 ${ }^{-/-}$MCEnC early and late passages. Genes from different pathways are clustered and separated by dashed lines.

(NBCe1, SLC4A4), which plays an essential role in the CEnC pump function, ${ }^{26}$ was downregulated fourfold in SLC4A11 KD pHCEnC and >100-fold in Slc4a11 ${ }^{-/-}$MCEnC (early and late passage). The downregulation of SLC4A4/Slc4a4 was verified by qPCR in SLC4A11 KD pHCEnC and Slc $4 a 11^{-/-}$ MCEnC (Fig. 3F), by western blot in SLC4A11 KD pHCEnC
(Fig. 3G) and by immunofluorescence staining for NBCe1 (SLC4A4) in the corneal endothelium of two individuals with CHED (Fig. 3H), which showed decreased NBCe1 expression compared to controls (Fig. 3I).

Next, functional measurement of $\mathrm{Na}^{+}$-dependent $\mathrm{HCO}_{3}{ }^{-}$ transport in $\mathrm{Slc}_{\mathrm{a}} \mathrm{I1}^{-/-}$MCEnC showed reduced $\mathrm{Na}^{+}$- 
bioRxiv preprint doi: https://doi.org/10.1101/868281; this version posted August 13, 2020. The copyright holder for this preprint (which was not certified by peer review) is the author/funder. All rights reserved. No reuse allowed without permission.
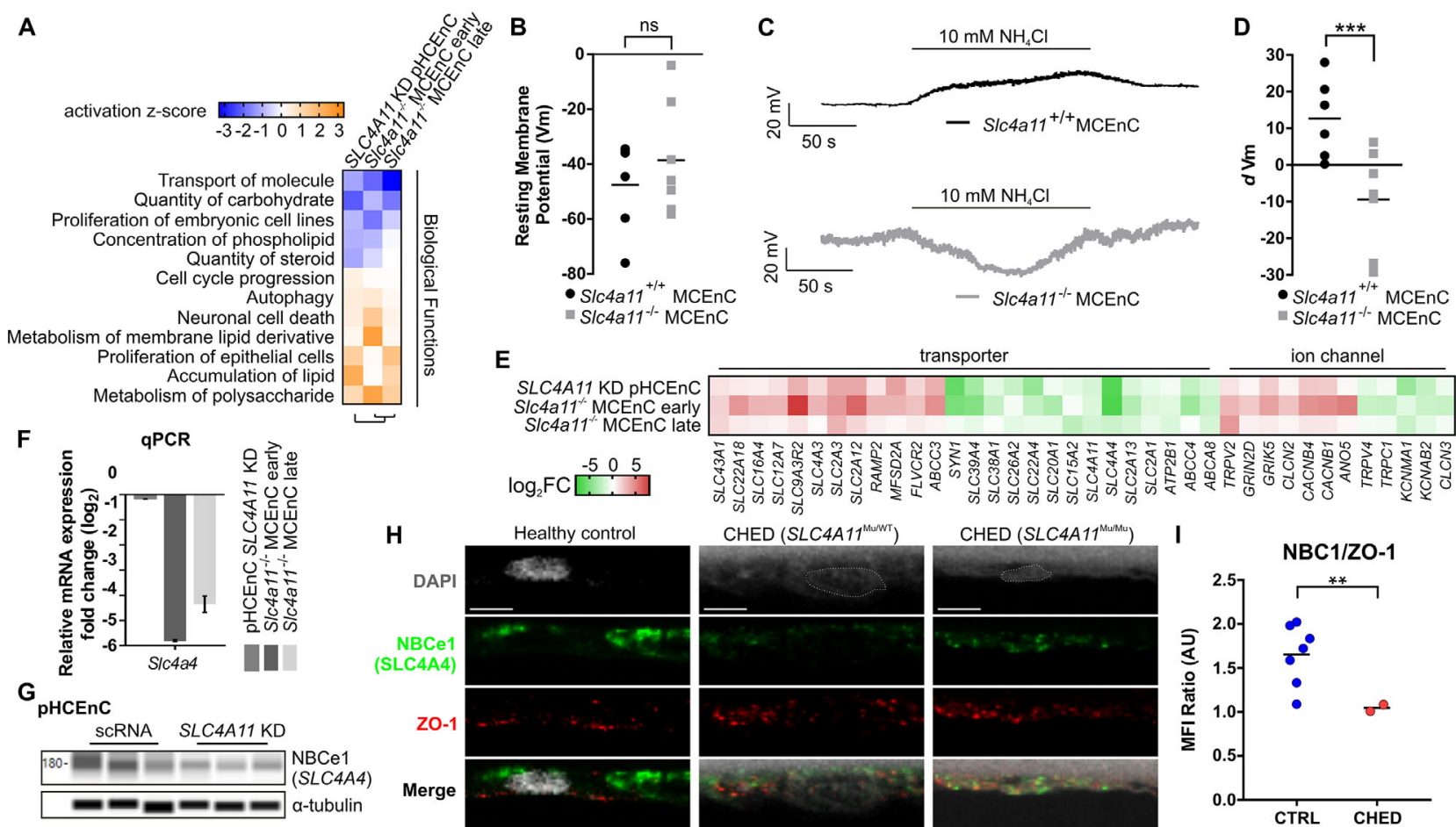
E
SLC4A11 KD pHCEnC
SlC4a11 $11^{-1 .} \mathrm{MCEnC}$ early
SIC4a11 $11^{-1}$ MCEnC late $\begin{array}{rrr}-5 & 0 & 5\end{array}$

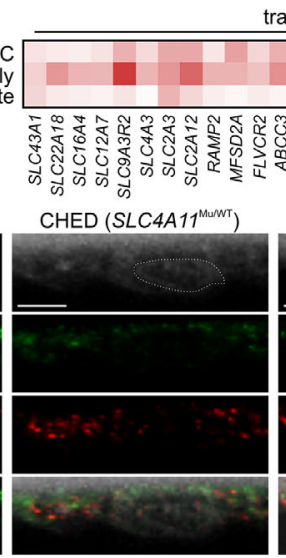

transporter ion channel
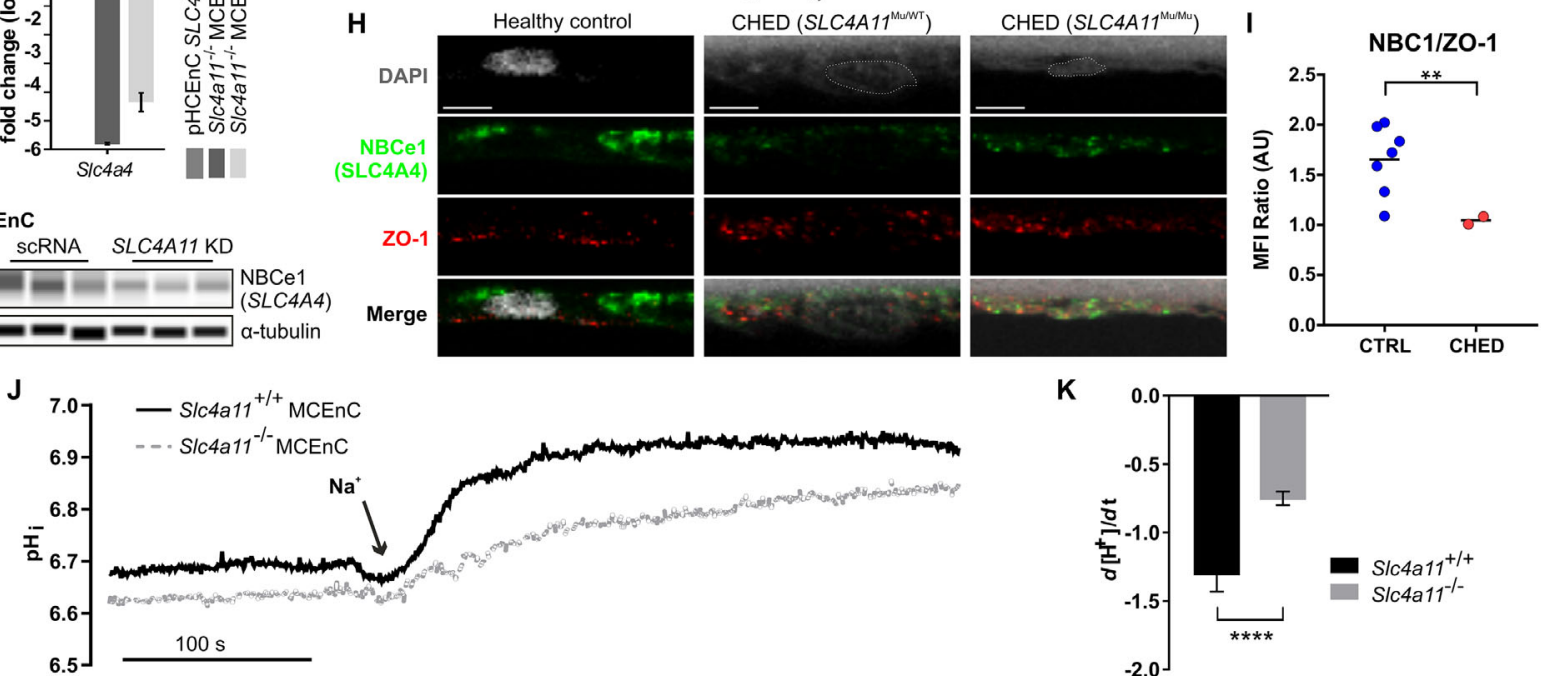

$\mathbf{K}$

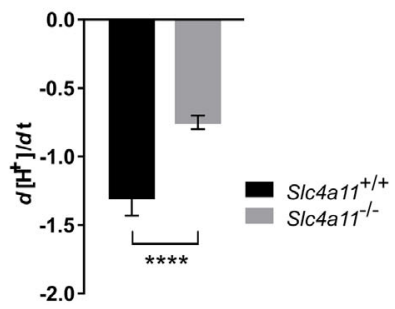

FigurE 3. SLC4A11 deficiency impacts corneal endothelial ion and solute transport function. (A) Heat map showing consensually enriched IPA biological function pathways from comparison of transcriptomes of SLC4A11 KD pHCEnC and Slc4a11 ${ }^{-/-}$MCEnC early and late passages (sorted by mean activation $z$-score). (B) Scatterplot of resting membrane potential $(\mathrm{Vm})$ in Slc4a11 ${ }^{+/+}(n=6)$ and $\operatorname{Slc} 4 a 11^{-/-}$ $(n=7)$ MCEnC. Two-tailed paired-samples $t$-test, $P=0.408$. (C) Representative trace of current-clamped single cell recording during 10

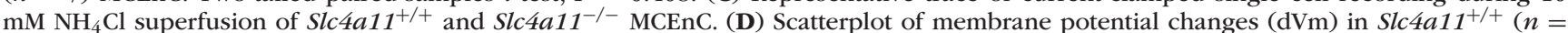
$6)$ and Slc4a11-/- $(n=7)$ MCEnC in response to $\mathrm{NH}_{4} \mathrm{Cl}$ superfusion. Monte Carlo resampling, two-tailed paired-samples $t$-test, difference between genotype $\mathrm{dVm}=-22.2(-34.8,-10) \mathrm{mV}, P=0.0069$. (E) Heat map showing common differentially expressed genes encoding ion channel and transporter proteins in SLC4A11 KD pHCEnC and early and late Slc4a11 ${ }^{-/-}$MCEnC. (F) The differential expression of Na ${ }^{+}$$\mathrm{HCO}_{3}{ }^{-}$transporter (NBCe1, encoded by SLC4A4) mRNA was validated by qPCR in separate RNA isolations from SLC4A11 KD pHCEnC and Slc4a11 ${ }^{-1-}$ MCEnC. (G) Western blot for NBCe1 in SLC4A11 KD pHCEnC and scRNA pHCEnC control showing decreased NBCe1 protein level in SLC4A11 KD pHCEnC. (H) Representative images of immunofluorescence staining for NBCe1 (green signal) and tight junction Zonula occludens-1 (ZO-1) (red signal) in corneal endothelium of two individuals with CHED and healthy control. Nuclei were stained with DAPI (gray signal). Scale bar: $5 \mu \mathrm{m}$. (I) Scatterplot of mean fluorescence intensity (MFI) ratio of NBCe1 over ZO-1 in corneal endothelium of two individuals with CHED and of seven healthy controls. Two-tailed unpaired $t$-test with Welch's correction, $P=0.0031$. (J) Representative trace of $\mathrm{pH}_{\mathrm{i}}$ response in $S l c 4 a 11^{-/-}$and Slc4a11 ${ }^{+/+}$MCEnC to the addition of extracellular $\mathrm{Na}^{+}$in $\mathrm{HCO}_{3}{ }^{-}$-containing solution. (K) Bar graph of the rate of intracellular $\left[\mathrm{H}^{+}\right]$change $\left(d\left[\mathrm{H}^{+}\right] / d \mathrm{t}\right)$ in $\operatorname{Slc} 4 a 11^{+/+}(n=6)$ and $\operatorname{Slc4a11^{-/-}}(n=8)$ MCEnC. Two-tailed unpaired $t$-test, $P<$ 0.0001 .

$\mathrm{HCO}_{3}{ }^{-}$co-transporter activity when compared to $\mathrm{Slc} 4 \mathrm{a} 11^{+/+}$ MCEnC (Fig. 3J), consistent with reduced NBCe1 expression. In Figure $3 \mathrm{~J}, \mathrm{pH}_{\mathrm{i}}$ was maintained at a low value when Slc $4 a 11^{-/-}$and Slc4a11 ${ }^{+/+}$MCEnC were perfused with a $28.3 \mathrm{mM}$ bicarbonate $\left(\mathrm{HCO}_{3}{ }^{-}\right)$solution that was $\mathrm{Na}^{+}$free. When switched to a bicarbonate solution containing $\mathrm{Na}^{+}$, $\mathrm{pH}_{\mathrm{i}}$ increased as NBCe1 started to move the weak base $\mathrm{HCO}_{3}{ }^{-}$inward using the $\mathrm{Na}^{+}$inward transmembrane electrochemical gradient. We determined the initial slope of this $\mathrm{pH}_{\mathrm{i}}$ rise to serve as an indirect measure of $\mathrm{Na}^{+}-\mathrm{HCO}_{3}{ }^{-}$ cotransport activity and observed a reduced $\mathrm{Na}^{+}$-dependent
$\mathrm{pH}_{\mathrm{i}}$ rise in $S l c 4 a 11^{-/-}$MCEC compared with Slc $4 A 11^{+/+}$ MCEnC (Figs. 3J, 3K).

\section{Mitochondria Dysfunction Leads to Reduced ATP Production}

Dilated mitochondria is a characteristic electron microscopy finding in CHED corneal endothelium, suggestive of mitochondrial involvement in the pathogenesis. ${ }^{68}$ Correspondingly, "mitochondria dysfunction" was the top enriched 
bioRxiv preprint doi: https://doi.org/10.1101/868281; this version posted August 13,2020 . The copyright holder for this preprint (which was not certified by peer review) is the author/funder. All rights reserved. No reuse allowed without permission.

Energy Shortage in SLC4A11 Deficient CEnC IOVS | July 2020 | Vol. 61 | No. 8 | Article 39 | 7

TABLE. Differentially Expressed Genes Encoding Ion Channels and Transporters in SLC4A11 KD pHCEnC, Slc4a11 ${ }^{-/-}$MCEnC Early, and MCEnC Late Sample Sets

Upregulated

Downregulated

\begin{tabular}{|c|c|c|}
\hline \multicolumn{3}{|l|}{ Ion channels } \\
\hline $\mathrm{Cl}^{-}$channels & CLCN2, ANO5 & CLCN3 \\
\hline $\mathrm{Ca}^{2+}$ channels & TRPV2, CACNB1, CACNB4 & TRPV4, TRPC1 \\
\hline $\mathrm{K}^{+}$channels & - & KCNAB2, KCNMA1 \\
\hline \multicolumn{3}{|l|}{ Transporters } \\
\hline $\mathrm{NH}_{3}: \mathrm{H}^{+}$transporter & - & $S L C 4 A 11$ \\
\hline $\mathrm{Na}^{+}-\mathrm{HCO}_{3}{ }^{-}$cotransporter & - & SLC4A4 \\
\hline $\mathrm{Ca}^{2+}$-ATPase & - & $A T P 2 B 1$ \\
\hline Glucose transporter & $S L C 2 A 3, S L C 2 A 12$ & $S L C 2 A 1, S L C 2 A 13, S L C 15 A 2$ \\
\hline Glutamine transporter & - & $S L C 38 A 1$ \\
\hline $\mathrm{Cl}^{-} / \mathrm{HCO}_{3}^{-}$exchanger & $S L C 4 A 3$ & - \\
\hline ATP-binding cassette transporters & $A B C C 3$ & $A B C A 8, A B C C 4$ \\
\hline $\mathrm{K}^{+}-\mathrm{Cl}^{-}$cotransporter & $S L C 12 A 7$ & - \\
\hline $\mathrm{Na}^{+} / \mathrm{H}^{+}$exchanger regulator & $S L C 9 A 3 R 2$ & - \\
\hline $\mathrm{Na}^{+}-\mathrm{HPO}_{3}{ }^{-}$cotransporter & - & SLC2OA1 \\
\hline Lactate transporter & SLC16A4 & - \\
\hline $\mathrm{Na}^{+}$-carnitine cotransporter & SLC22A18 & $S L C 22 A 4$ \\
\hline $\mathrm{SO}_{4}^{2-}$ transporter & - & SLC26A2 \\
\hline
\end{tabular}

canonical pathway in the pHCEnC and MCEnC early and late sample sets (ranked by $P$ value, Fig. 4A). Additionally, in the list of 1041 genes differentially expressed in the same direction in the pHCEnC and MCEnC early and late sample sets, genes encoding proteins involved in the mitochondria electron transport chain, mediating mitochondrial ATP flux, import machinery and translation machinery showed a generalized decreased expression (Figs. 4B, 4C) ${ }^{69}$ Because transcriptomic analysis also suggested that "autophagy" was activated (Fig. 3A) in SLC4A11 KD pHCEnC and Slc4a11 ${ }^{-/-}$MCEnC, we examined the differential expression of $S T X 17 / S t x 17$, which encodes SNARE protein Syntaxin 17 (STX17), a mitophagy initiator facilitating the removal of dysfunctional mitochondria. $^{70,71}$ STX17/Stx 17 was upregulated in the SLC4A11 KD pHCEnC and Slc4a11 ${ }^{-/-}$MCEnC transcriptomes (Fig. 4D), a finding that was validated by $\mathrm{qPCR}$ in $S L C 4 A 11 \mathrm{KD}$ pHCEnC and Slc4a11-/- MCEnC (Fig. 4E), by western blot in SLC4A11 KD pHCEnC (Fig. 4F) and by immunofluorescence in CHED corneal endothelium, which demonstrated increased STX17 staining intensity and co-localization with mitochondria marker COX4 compared with healthy controls (Fig. 4G). Significantly decreased COX4 expression was observed in CHED corneal endothelium, indicating reduced mitochondrial density (Figs. 4G, 4I) and resulting in increased STX17 abundance relative to the mitochondrial density (STX17/COX4) (Fig. 4H). Staining CHED endothelium with another mitochondrial marker, cytochrome $c$, also showed consistently decreased staining intensity (Figs. 4J, 4K).

Given the evidence indicating mitochondrial dysfunction and reduced mitochondrial density in the setting of reduced SLC4A11 expression, we hypothesized that these would result in insufficient ATP energy supply to maintain the $\mathrm{Na}^{+}-\mathrm{K}^{+}$-ATPase-driven corneal endothelial pump and the cornea edema that characterizes CHED. Thus, we performed a direct measurement of the steady-state ATP levels in SLC4A11 KD pHCEnC and Slc4a11-/- MCEnC, which revealed reduced ATP concentrations compared to control scRNA pHCEnC and Slc $4 a 11^{+/+}$MCEnC, respectively (Figs. 4L, 4M).

\section{Transcriptomic Changes Associated with Loss of SLC4A11 Are Mediated by Activation of AMP-Activated Protein Kinase-p53 Pathway}

To identify the upstream signaling pathway responsible for the observed transcriptomic changes in $S L C 4 A 11 \mathrm{KD}$ pHCEnC and Slc4a11 ${ }^{-1-}$ MCEnC, we performed upstream regulator prediction in IPA, which identified p53 (encoded by the TP53 gene) as the top candidate transcription factor (Fig. 5A). Western blot analysis in SLC4A11 KD pHCEnC demonstrated increased Ser15 phosphorylation of p53 compared to scRNA pHCEnC controls (Fig. 5B), indicative of post-translational activation of p53 transcriptional activity. Similarly, in $S l c 4 a 11^{-/-}$MCEnC, we observed increased Ser18 phosphorylation of p53 (corresponding to

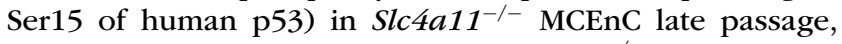
although this was not observed in Slc4a11-/- MCEnC early passage (Fig. 5C). However, there was increased total p53 levels in both $S l c 4 a 11^{-/-}$MCEnC early and late passages (Figs. 5C, 5D), indicative of transcriptional activation of $\mathrm{p} 53$.

We then sought to identify the kinase responsible for the Ser15 (Ser18 in mouse) phosphorylation and transcriptional activation of p53 in SLC4A11 KD pHEnC and Slc $4 a 11^{-/-}$ MCEnC. Given the observed ATP depletion in SLC4A11 KD pHEnC and $S l c 4 a 11^{-/-}$MCEnC, as well as the reported capacity of the cellular ATP sensor AMP-activated protein kinase (AMPK) to mediate Ser15 (Ser18 in mouse) phosphorylation and transcriptional activation of $\mathrm{p} 53$, we investigated the potential role of AMPK..$^{72-74}$ In the setting of a decreased ATP-to-adenosine diphosphate (ADP) or ATP-toAMP ratio, the AMPK catalytic $\alpha$ subunit will be phosphorylated at Thr172, whereas phosphorylation of the regulatory $\beta 1$ subunit at Ser182 is not dependent upon cellular ATP levels. $^{75}$ In SLC4A11 KD pHCEnC and Slc $4 a 11^{-/-}$MCEnC, we observed increased Thr172 phosphorylation of AMPK $\alpha$ and no change in Ser182 phosphorylation of AMPK $\beta 1$ (Figs. 5B, 5C). Examination of another downstream substrate of AMPK, Unc-51 like autophagy activating kinase 1 (ULK1), showed increased phosphorylation (Ser555) in SLC4A11 KD pHCEnC compared with scRNA pHCEnC (Figs. 5E, 5F). 
bioRxiv preprint doi: https://doi.org/10.1101/868281; this version posted August 13,2020 . The copyright holder for this preprint (which was not certified by peer review) is the author/funder. All rights reserved. No reuse allowed without permission.

A

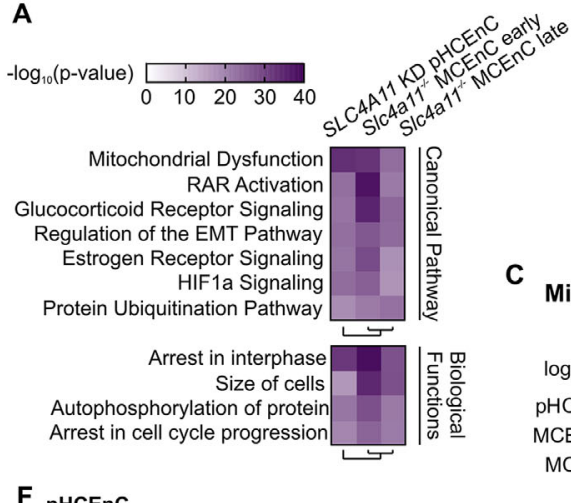

$F_{\text {pHCEnC }}$

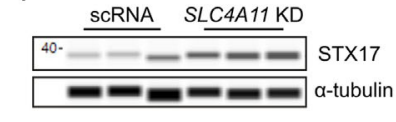

I Mitochondria (COX4)

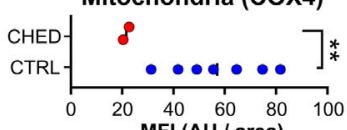

MFI (AU / area)

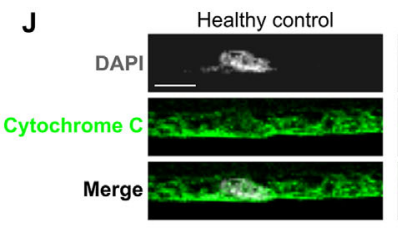

K
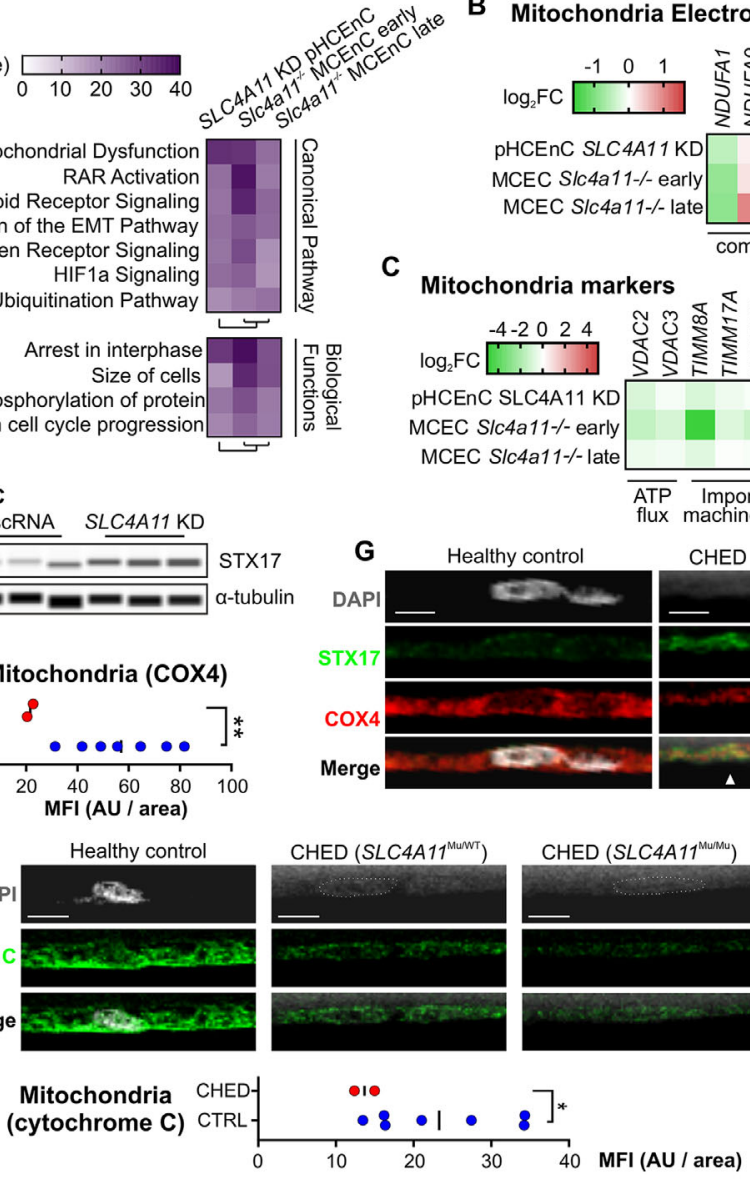
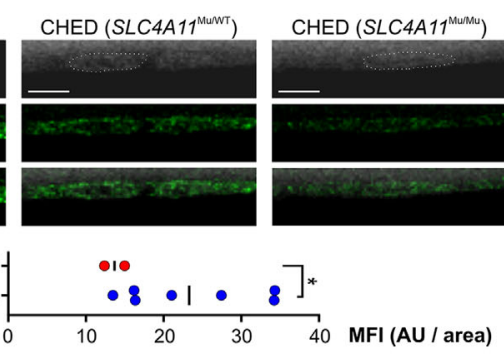

B

pHCEnC SLC4A11 KD

MCEC SIC4a11-/- early MCEC SIC4a11-/ late

C Mitochondria markers

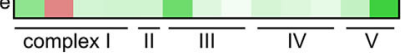

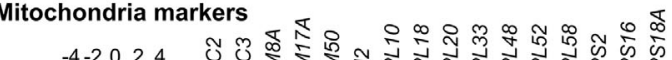

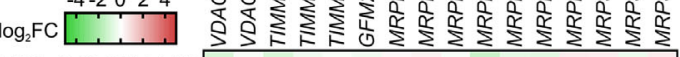
pHCEnC SLC4A11 KD MCEC SIC4a11-/- early MCEC SIc4a11-/ late

$$
\begin{aligned}
& \overline{\text { ATP }} \overline{\text { Import }} \\
& \text { flux machinery }
\end{aligned}
$$

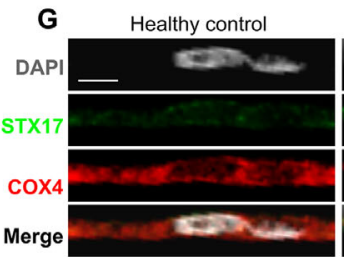

CHED (SLC4A11 $\left.{ }^{\text {MUNT }}\right)$

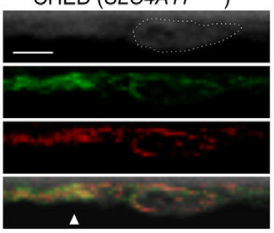

CHED (SLC4A11 $\left.1^{\text {MUMu }}\right)$

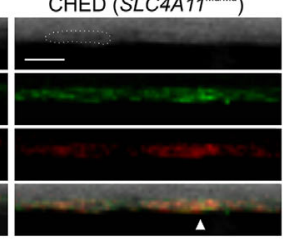

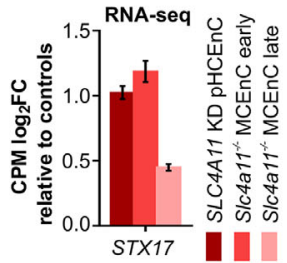

E

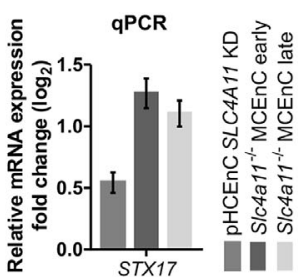

H STX17/COX4

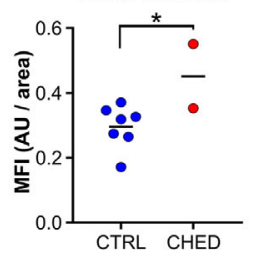

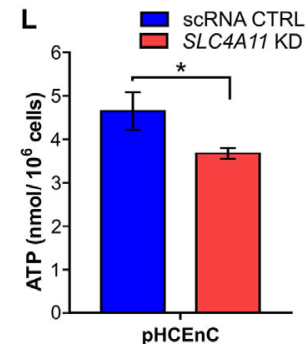

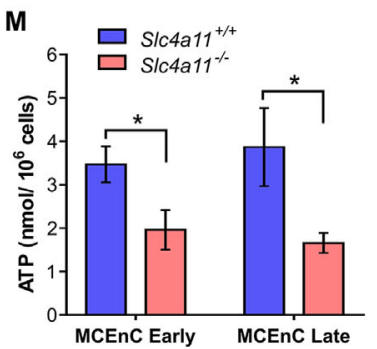

Figure 4. Mitochondria dysfunction in SLC4A11-deficient corneal endothelium. (A) Heat map of commonly enriched canonical and biological function pathways in transcriptomes of SLC4A11 KD pHCEnC and early and late Slc4a11-1- MCEnC. (B) Transcript levels of differentially expressed enzyme coding genes involved in mitochondria electron transport chain. (C) Transcript levels of differentially expressed protein coding genes that serve as mitochondrial functional markers. (D) Bar graph of transcriptome data showing transcript-level fold change of STX17 in SLC4A11 KD pHCEnC and Slc4a11 ${ }^{-1-}$ MCEnC compared to controls. (E) Bar graph of qPCR showing mRNA expression-level fold change of STX17 in separate RNA isolations from SLC4A11 KD pHCEnC and Slc4a11 ${ }^{-}$MCEnC compared to controls. (F) Western blot of STX17 protein level in SLC4A11 KD pHCEnC and in scRNA pHCEnC controls. (G) Representative images of immunofluorescence staining for STX17 (green signal) and mitochondria marker COX4 (red signal) in corneal endothelium of two individuals with CHED and healthy control. Nuclei were stained with DAPI (gray signal). Co-localization of STX17 (green) and COX4 (red) was seen in CHED corneal

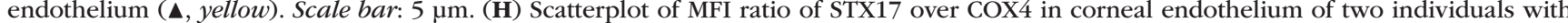
CHED and of seven healthy controls. Two-tailed unpaired $t$-test with Welch's correction, $P=0.0483$. (I) Scatterplot of MFI of COX4 in corneal endothelium of two individuals with CHED and of seven healthy controls. Two-tailed unpaired $t$-test with Welch's correction, $P=0.0018$ (J) Representative images of immunofluorescence staining for cytochrome $c$ (green signal) in corneal endothelium of two individuals with CHED and of seven healthy controls. Nucleus were stained with DAPI (gray signal). Scale bar: $5 \mu \mathrm{m}$. (K) Scatterplot of MFI of cytochrome $c$ in corneal endothelium of two individuals with CHED and of seven healthy controls. Two-tailed unpaired $t$-test with Welch's correction, $P=0.0304$. (L) Bar graph summary of intracellar ATP levels measured in SLC4A11 KD pHCEnC and scRNA pHCEnC controls. One-tailed unpaired $t$-test, $P=0.0281(n=6)$. (M) Bar graph summary of intracellar ATP levels measured in early passage (two-tailed unpaired $t$-test,

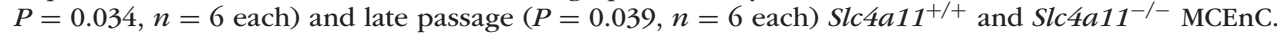

\section{Discussion}

In this manuscript, we utilized primary human CEnC, a CEnC cell line from Slc4a11 ${ }^{-1-}$ mice $^{23}$ and corneal specimens from individuals with CHED to investigate the causes of CEnC dysfunction that characterize each of the SLC4A11associated corneal endothelial dystrophies (CHED, FECD, and Harboyan syndrome). Although several previous reports have elucidated possible roles for mitochondrial uncoupling, ER unfolded protein response, oxidative stress, and apoptosis in SLC4A11-deficient human and mouse cell lines, ${ }^{9,20,21,30,50,76}$ none utilized primary human CEnC, and only one report examined CHED patient corneal endothe- lium, in which increased oxidative stress was demonstrated. ${ }^{20}$ We identified ATP depletion in CEnC with reduced SLC4A11, in both transient (72 hours) SLC4A11 knockdown in pHCEnC and permanent Slc4a11 knockout in MCEnC. The reduced CEnC ATP levels provide a proposed pathogenesis for the CEnC dysfunction that characterizes the SLC4A11-associated corneal endothelial dystrophies. The fact that ATP depletion and ATP-sensor AMPK $\alpha$ activation were detected within 72 hours of SLC4A11 knockdown in pHCEnC suggests that energy shortage from the loss of SLC4A11 is likely among the initial steps in the pathogenesis of SLC4A11-associated corneal endothelial dystrophies. 
bioRxiv preprint doi: https://doi.org/10.1101/868281; this version posted August 13, 2020. The copyright holder for this preprint (which was not certified by peer review) is the author/funder. All rights reserved. No reuse allowed without permission.
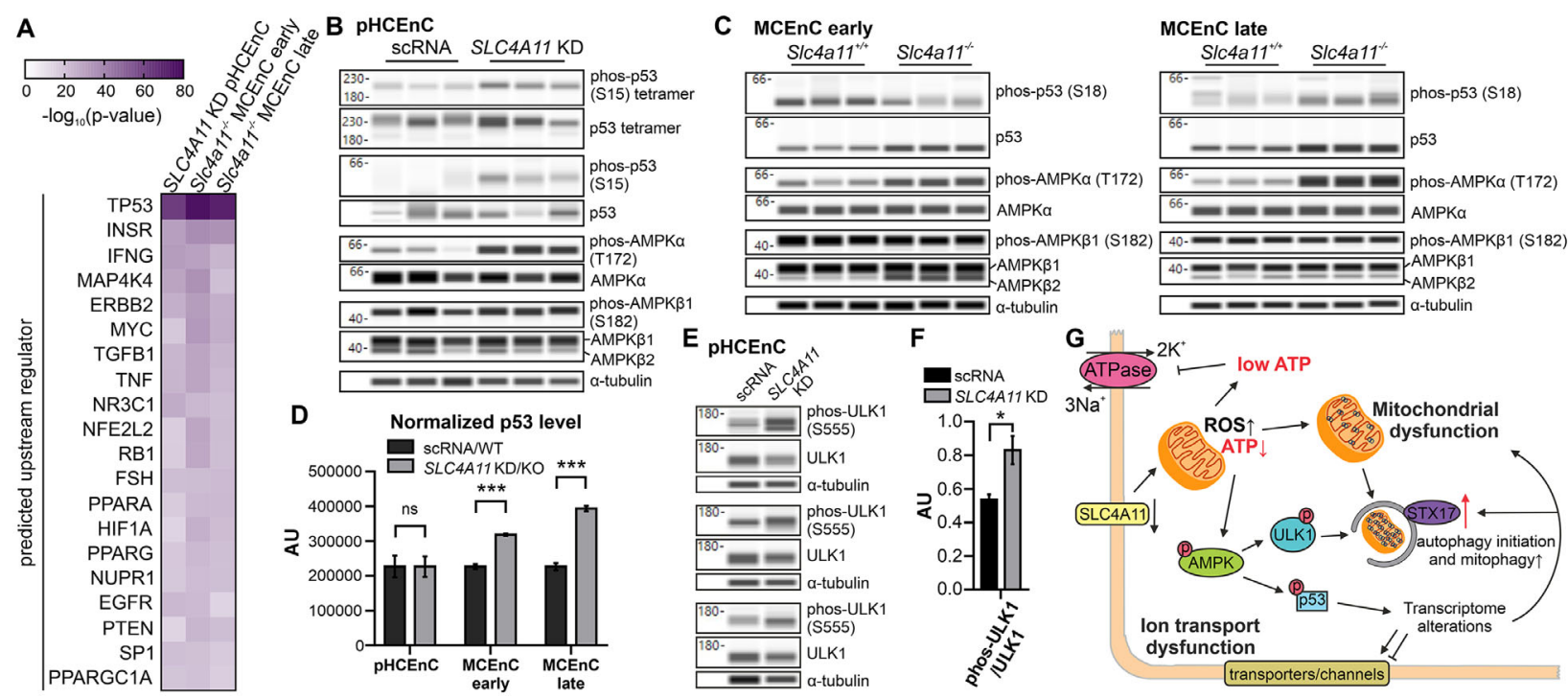

FIGURE 5. Activation of AMPK-p53 pathway in SLC4A11-deficient corneal endothelium. (A) Heat map of shared predicted upstream regulators of transcriptomes of $S L C 4 A 11 \mathrm{KD}$ pHCEnC and early and late $S l c 4 a 11^{-/-}$MCEnC (sorted by mean adjusted $P$ value). (B) Western blot analysis of SLC4A11 KD pHCEnC and scRNA controls for Ser15 phosphorylated p53 (phos-p53, S15), total p53, Thr172 phosphorylated AMPK $\alpha$ (phosAMPK $\alpha$, T172), total AMPK $\alpha$, Ser182 phosphorylated AMPK $\beta$ (phos-AMPK $\beta 1$, S182), and total AMPK $\beta 1$ and $\beta 2$. (C) Western blot analysis of early and late Slc4a11 $1^{+/}$and Slc4a11-/- MCEnC for Ser18 phosphorylated p53 (phos-p53, S18), total p53, Thr172 phosphorylated AMPK $\alpha$ (phos-AMPK $\alpha$, T172), total AMPK $\alpha$, Ser182 phosphorylated AMPK $\beta$ (phos-AMPK $\beta 1$, S182), and total AMPK $\beta 1$ and $\beta 2$. (D) Bar graph summary of western blot densitometry results for normalized total p53 level in SLC4A11 KD pHCEnC versus scRNA pHCEnC (two-tailed unpaired-samples $t$-test $(P>0.99))$, in early passage $S l c 4 a 11^{-/-}$versus $S l c 4 a 11^{+/+}$MCEnC $(P=0.00027)$ and in late passage $S l c 4 a 11^{-/-}$ versus Slc4a11 ${ }^{+/+}$MCEnC $(P=0.00021)$. (E) Western blot analysis of SLC4A11 KD pHCEnC and scRNA control for Ser555 phosphorylated ULK1 (phos-ULK1, S555) and total ULK1. (F) Bar graph summary of western blot densitometry results from biological triplicates of SLC4A11 KD pHCEnC and scRNA pHCEnC controls for the ratio of phosphorylated ULK1/total ULK1 (phos-ULK1/ULK1). Two-tailed unpaired $t$-test, $P=0.030$. (G) Schematic summary of the downstream molecular events as a result of SLC4A11 deficiency in corneal endothelial cells.

Although the prevailing hypothesis regarding the pathogenesis of CHED is that the majority of SLC4A11 mutations result in protein misfolding and retention in the $\mathrm{ER}, 5,6,50,51$ we provide preliminary evidence that mutant SLC4A11 protein is not retained in the ER of the corneal endothelium in CHED. In addition, immunostaining of corneal endothelium from two individuals with CHED did not show a reduced level of the SLC4A11 mutant protein, consistent with a previous report that CHED corneal endothelium does not demonstrate reduced SLC4A11 expression at the mRNA level. ${ }^{20}$ Instead, our data, which we recognize is derived from a very limited number of observations, support the alternative hypothesis that identified $S L C 4 A 11$ mutations affect the ion transport function of SLC4A11 protein in the corneal endothelium. ${ }^{17,52,53}$

We used a comparative transcriptomics approach based on the observation of phenotypic similarities between CHED and the Slc4a11-/- mouse corneal phenotype..$^{77,78}$ This approach is based on the high degree of gene orthology between mouse and human and the organ-dominated hierarchical clustering observed across mammals on real gene expression data. ${ }^{79}$ Such a comparative transcriptomic approach enables the differentiation of transcriptome alterations attributable to the loss of SLC4A11/Slc4a11 in pHCEnC and MCEnC from confounding biological or technical factors associated with each cell preparation, including differences in primary cell isolation and passaging, siRNA treatment, cell line immortalization, and cell culture media. ${ }^{80}$ With this approach, we identified generalized inhibition of multiple metabolic pathways, as well as mitochondria dysfunction in both SLC4A11 KD pHCEnC and Slc $4 a 11^{-/-}$MCEnC. We also identified the reduced expres- sion of several ion channels and transporters, including NBCe1, and a decrease in $\mathrm{Na}^{+}$-dependent $\mathrm{HCO}_{3}{ }^{-}$transport activity, which was in contrast to a previous functional examination of $\mathrm{HCO}_{3}{ }^{-}$transport in Slc $4 a 11^{-/-}$MCEnC that did not reveal any difference in comparison to $S l c 4 a 11^{+/+}$ MCEnC. ${ }^{23}$ The discrepancy is likely because previous experiments were performed in a $\mathrm{Na}^{+}$-rich, $\mathrm{HCO}_{3}{ }^{-}$-free solution with subsequent reintroduction of $\mathrm{HCO}_{3}{ }^{-}$, whereas we performed the experiment in a $\mathrm{Na}^{+}$-free, $\mathrm{HCO}_{3}{ }^{-}$-rich solution with subsequent reintroduction of $\mathrm{Na}^{+}$. While a previous report provided an estimate of $\mathrm{HCO}_{3}{ }^{-}$transport activities in $S l c 4 a 11^{-1-}$ MCEnC, ${ }^{23}$ we provided an estimate of $\mathrm{Na}^{+}$-dependent $\mathrm{HCO}_{3}{ }^{-}$transport activities. We attributed the observed transcriptomic changes in $S L C 4 A 11 \mathrm{KD}$ pHCEnC and Slc4a11 ${ }^{-/-}$MCEnC to activation of the AMPK-p53 pathway. Although post-translational activation (phosphorylation) of p53 was observed with transient SLC4A11 knockdown in pHCEnC, transcriptional activation (upregulation) of p53 was observed with permanent SLC4A11 knockout in MCEnC, both attributed to AMPK $\alpha$ activation. ${ }^{73}$ The observation that ATP depletion and AMPK activation occur within 72 hours after SLC4A11 knockdown suggests that they are likely to be among the initial cellular events in response to SLC4A11 deficiency.

In summary, we postulate that SLC4A11 deficiency leads to $\mathrm{CEnC}$ dysfunction primarily through decreased generation of ATP via glutaminolysis to fuel the $\mathrm{Na}^{+} / \mathrm{K}^{+}$-ATPase-driven endothelial pump. The decreased ATP levels also result in the activation of AMPK and its downstream substrates, p53 and ULK1, leading to transcriptome alterations and increased mitophagy, respectively. Similarly, given the role of SLC4A11 in preventing oxidative damage, the loss of 
bioRxiv preprint doi: https://doi.org/10.1101/868281; this version posted August 13,2020 . The copyright holder for this preprint (which was not certified by peer review) is the author/funder. All rights reserved. No reuse allowed without permission.

Energy Shortage in SLC4A11 Deficient CEnC

SLC4A11 leads to increased mitochondrial ROS production, ${ }^{30}$ subsequent mitochondria dysfunction, and increased mitophagy (Fig. 5G). This proposed pathogenesis supports the use of the $S l c 4 a 11^{-/-}$mice, in which the alterations resulting from Slc4a11 depletion mirror those observed in SLC4A11 KD pHCEnC, as a model for the SLC4A11associated corneal endothelial dystrophies and indicates a favorable translational potential for therapeutic approaches shown to be efficacious in the $S l c 4 a 11^{-/-}$mice.

\section{Acknowledgments}

Supported by National Eye Institute Grants (1R01EY022082, AJA; P30EY000331 and R01EY029817, APS); the Walton Li Chair in Cornea and Uveitis (AJA); the Stotter Revocable Trust (SEI Cornea Division); an unrestricted grant from Research to Prevent Blindness (AJA); a National Institute of Diabetes and Digestive and Kidney Diseases grant (1R01DK077162, IK); the Allan Smidt Charitable Fund (IK); Ralph Block Family Foundation (IK); and Knights Templar Eye Foundation Career Starter Grant (WZ).

Disclosure: W. Zhang, None; R. Frausto, None; D.D. Chung, None; C.G. Griffis, None; L. Kao, None; A. Chen, None; R. Azimov, None; A.P. Sampath, None; I. Kurtz, None; A.J. Aldave, None

\section{References}

1. Frausto RF, Wang C, Aldave AJ. Transcriptome analysis of the human corneal endothelium. Invest Ophthalmol Vis Sci. 2014;55:7821-7830.

2. Chng Z, Peh GS, Herath WB, et al. High throughput gene expression analysis identifies reliable expression markers of human corneal endothelial cells. PLoS One. 2013;8:e67546.

3. Chen Y, Huang K, Nakatsu MN, Xue Z, Deng SX, Fan G. Identification of novel molecular markers through transcriptomic analysis in human fetal and adult corneal endothelial cells. Hum Mol Genet. 2013;22:1271-1279.

4. Aldahmesh MA, Khan AO, Meyer BF, Alkuraya FS. Mutational spectrum of SLC4A11 in autosomal recessive CHED in Saudi Arabia. Invest Ophthalmol Vis Sci. 2009;50:41424145.

5. Vithana EN, Morgan PE, Ramprasad V, et al. SLC4A11 mutations in Fuchs endothelial corneal dystrophy. Hum Mol Genet. 2008;17:656-666.

6. Vithana EN, Morgan P, Sundaresan P, et al. Mutations in sodium-borate cotransporter SLC4A11 cause recessive congenital hereditary endothelial dystrophy (CHED2). Nat Genet. 2006;38:755-757.

7. Desir J, Moya G, Reish O, et al. Borate transporter SLC4A11 mutations cause both Harboyan syndrome and non-syndromic corneal endothelial dystrophy. J Med Genet. 2007;44:322-326.

8. Dana MR, Moyes AL, Gomes JA, et al. The indications for and outcome in pediatric keratoplasty. A multicenter study. Ophthalmology. 1995;102:1129-1138.

9. Siddiqui S, Zenteno JC, Rice A, et al. Congenital hereditary endothelial dystrophy caused by SLC4A11 mutations progresses to Harboyan syndrome. Cornea. 2014;33:247251.

10. Lorenzetti DW, Uotila MH, Parikh N, Kaufman HE. Central cornea guttata. Incidence in the general population. $\mathrm{Am} \mathrm{J}$ Ophthalmol. 1967;64:1155-1158.

11. Eye Bank Association of America. 2018 eye banking statistical report. Available at: https://restores
IOVS | July 2020 | Vol. 61 | No. 8 | Article 39 | 10

ight.org/wp-content/uploads/2019/03/2018_Statistical_ Report-Complete-1.pdf. Accessed July 6, 2020.

12. Gain P, Jullienne $\mathrm{R}, \mathrm{He} \mathrm{Z}$, et al. Global survey of corneal transplantation and eye banking. JAMA Ophthalmol. 2016;134:167-173.

13. Dorrepaal SJ, Cao KY, Slomovic AR. Indications for penetrating keratoplasty in a tertiary referral centre in Canada, 1996-2004. Can J Ophthalmol. 2007;42:244-250.

14. Ghosheh FR, Cremona FA, Rapuano CJ, et al. Trends in penetrating keratoplasty in the United States 1980-2005. Int Ophthalmol. 2008;28:147-153.

15. Zhang W, Ogando DG, Bonanno JA, Obukhov AG. Human SLC4A11 is a Novel $\mathrm{NH}^{3} / \mathrm{H}^{+}$co-transporter. J Biol Chem. 2015;290:16894-16905.

16. Myers EJ, Marshall A, Jennings ML, Parker MD. Mouse Slc4a11 expressed in Xenopus oocytes is an ideally selective $\mathrm{H}^{+} / \mathrm{OH}^{-}$conductance pathway that is stimulated by rises in intracellular and extracellular pH. Am J Physiol Cell Physiol. 2016;311:C945-C959.

17. Vilas GL, Loganathan SK, Liu J, et al. Transmembrane waterflux through SLC4A11: a route defective in genetic corneal diseases. Hum Mol Genet. 2013;22:4579-4590.

18. Ogando DG, Jalimarada SS, Zhang W, Vithana EN, Bonanno JA. SLC4A11 is an EIPA-sensitive $\mathrm{Na}(+)$ permeable pHi regulator. Am J Physiol Cell Physiol. 2013;305:C716-C727.

19. Kao L, Azimov R, Shao XM, et al. Multifunctional ion transport properties of human SLC4A11: comparison of the SLC4A11-B and SLC4A11-C variants. Am J Physiol Cell Physiol. 2016;311:C820-C830.

20. Guha S, Chaurasia S, Ramachandran C, Roy S. SLC4A11 depletion impairs NRF2 mediated antioxidant signaling and increases reactive oxygen species in human corneal endothelial cells during oxidative stress. Sci Rep. 2017;7:4074.

21. Liu J, Seet LF, Koh LW, et al. Depletion of SLC4A11 causes cell death by apoptosis in an immortalized human corneal endothelial cell line. Invest Ophthalmol Vis Sci. 2012;53:3270-3279.

22. Zhang W, Li H, Ogando DG, et al. Glutaminolysis is essential for energy production and ion transport in human corneal endothelium. EBioMedicine. 2017;16:292-301.

23. Zhang W, Ogando DG, Kim ET, et al. Conditionally immortal Slc4a11 ${ }^{-/}$mouse corneal endothelial cell line recapitulates disrupted glutaminolysis seen in Slc4a11 ${ }^{-/-}$ mouse model. Invest Ophthalmol Vis Sci. 2017;58:37233731.

24. Younger ST, Kenzelmann-Broz D, Jung H, Attardi LD, Rinn JL. Integrative genomic analysis reveals widespread enhancer regulation by $\mathrm{p} 53$ in response to DNA damage. Nucleic Acids Res. 2015;43:4447-4462.

25. Edelhauser HF. The balance between corneal transparency and edema: the Proctor Lecture. Invest Ophthalmol Vis Sci. 2006;47:1754-1767.

26. Bonanno JA. Molecular mechanisms underlying the corneal endothelial pump. Exp Eye Res. 2012;95:2-7.

27. Srinivas SP. Dynamic regulation of barrier integrity of the corneal endothelium. Optom Vis Sci. 2010;87:E239-254.

28. Riley MV, Winkler BS, Peters MI, Czajkowski CA. Relationship between fluid transport and in situ inhibition of $\mathrm{Na}(+)-\mathrm{K}+$ adenosine triphosphatase in corneal endothelium. Invest Ophthalmol Vis Sci. 1994;35:560-567.

29. Waring GO, 3rd, Bourne WM, Edelhauser HF, Kenyon KR. The corneal endothelium. Normal and pathologic structure and function. Ophthalmology. 1982;89:531-590.

30. Ogando DG, Choi M, Shyam R, Li S, Bonanno JA. Ammonia sensitive SLC4A11 mitochondrial uncoupling reduces glutamine induced oxidative stress. Redox Biol. 2019;26:101260. 
bioRxiv preprint doi: https://doi.org/10.1101/868281; this version posted August 13,2020 . The copyright holder for this preprint (which was not certified by peer review) is the author/funder. All rights reserved. No reuse allowed without permission.

31. Jiao X, Sultana A, Garg P, et al. Autosomal recessive corneal endothelial dystrophy (CHED2) is associated with mutations in SLC4A11.J Med Genet. 2007;44:64-68.

32. Hemadevi B, Veitia RA, Srinivasan M, et al. Identification of mutations in the SLC4A11 gene in patients with recessive congenital hereditary endothelial dystrophy. Arch Ophthalmol. 2008;126:700-708.

33. Sultana A, Garg P, Ramamurthy B, Vemuganti GK, Kannabiran C. Mutational spectrum of the SLC4A11 gene in autosomal recessive congenital hereditary endothelial dystrophy. Mol Vis. 2007;13:1327-1332.

34. Aldave AJ, Yellore VS, Bourla N, et al. Autosomal recessive CHED associated with novel compound heterozygous mutations in SLC4A11. Cornea. 2007;26:896-900.

35. Ramprasad VL, Ebenezer ND, Aung T, et al. Novel SLC4A11 mutations in patients with recessive congenital hereditary endothelial dystrophy (CHED2). Mutation in brief $\# 958$. Online. Hum Mutat. 2007;28:522-523.

36. Shah SS, Al-Rajhi A, Brandt JD, et al. Mutation in the SLC4A11 gene associated with autosomal recessive congenital hereditary endothelial dystrophy in a large Saudi family. Ophthalmic Genet. 2008;29:41-45.

37. Kumar A, Bhattacharjee S, Prakash DR, Sadanand CS. Genetic analysis of two Indian families affected with congenital hereditary endothelial dystrophy: two novel mutations in SLC4A11. Mol Vis. 2007;13:39-46.

38. Paliwal P, Sharma A, Tandon R, et al. Congenital hereditary endothelial dystrophy - mutation analysis of SLC4A11 and genotype-phenotype correlation in a North Indian patient cohort. Mol Vis. 2010;16:2955-2963.

39. Liskova P, Dudakova L, Tesar V, et al. Detailed assessment of renal function in a proband with Harboyan syndrome caused by a novel homozygous SLC4A11 nonsense mutation. Ophthalmic Res. 2015;53:30-35.

40. Kodaganur SG, Kapoor S, Veerappa AM, et al. Mutation analysis of the SLC4A11 gene in Indian families with congenital hereditary endothelial dystrophy 2 and a review of the literature. Mol Vis. 2013;19:1694-1706.

41. Park SH, Jeong HJ, Kim M, Kim MS. A novel nonsense mutation of the SLC4A11 gene in a Korean patient with autosomal recessive congenital hereditary endothelial dystrophy. Cornea. 2013;32:e181-e182.

42. Kumawat BL, Gupta R, Sharma A, Sen S, Gupta $S$, Tandon R. Delayed onset of congenital hereditary endothelial dystrophy due to compound heterozygous SLC4A11 mutations. Indian J Ophthalmol. 2016;64:492495.

43. Kim JH, Ko JM, Tchah H. Fuchs endothelial corneal dystrophy in a heterozygous carrier of congenital hereditary Endothelial dystrophy type 2 with a novel mutation in SLC4A11. Ophthalmic Genet. 2015;36:284-286.

44. Kaul H, Suman M, Khan Z, Ullah MI, Ashfaq UA, Idrees S. Missense mutation in SLC4A11 in two Pakistani families affected with congenital hereditary endothelial dystrophy (CHED2). Clin Exp Optom. 2016;99:73-77.

45. Cunnusamy K, Bowman CB, Beebe W, Gong X, Hogan RN, Mootha VV. Congenital corneal endothelial dystrophies resulting from novel de novo mutations. Cornea. 2016;35:281-285.

46. Hand CK, McGuire M, Parfrey NA, Murphy CC. Homozygous SLC4A11 mutation in a large Irish CHED2 pedigree. Ophthalmic Genet. 2017;38:148-151.

47. Brejchova K, Dudakova L, Skalicka P, et al. IPSC-derived corneal endothelial-like cells act as an appropriate model system to assess the impact of SLC4A11 variants on premRNA splicing. Invest Ophthalmol Vis Sci. 2019;60:30843090.

48. Moazzeni H, Javadi MA, Asgari D, et al. Observation of nine previously reported and 10 non-reported SLC4A11 mutations among 20 Iranian CHED probands and identification of an $M P D Z$ mutation as possible cause of CHED and FECD in one family. Br J Ophthalmol. 2019;e314377, doi:10.1136/bjophthalmol-2019-314377.

49. Alka K, Casey JR. Ophthalmic nonsteroidal antiinflammatory drugs as a therapy for corneal dystrophies caused by SLC4A11 mutation. Invest Ophthalmol Vis Sci. 2018;59:4258-4267.

50. Alka K, Casey JR. Molecular phenotype of SLC4A11 missense mutants: setting the stage for personalized medicine in corneal dystrophies. Hum Mutat. 2018;39:676690.

51. Malhotra D, Loganathan SK, Chiu AM, Lukowski CM, Casey JR. Human corneal expression of SLC4A11, a gene mutated in endothelial corneal dystrophies. Sci Rep. 2019;9:9681.

52. Li S, Hundal KS, Chen X, et al. R125H, W240S, C386R, and V507I SLC4A11 mutations associated with corneal endothelial dystrophy affect the transporter function but not trafficking in PS120 cells. Exp Eye Res. 2019;180:86-91.

53. Kao L, Azimov R, Abuladze N, Newman D, Kurtz I. Human SLC4A11-C functions as a DIDS-stimulatable $\mathrm{H}(+)(\mathrm{OH}(-))$ permeation pathway: partial correction of R109H mutant transport. Am J Physiol Cell Physiol. 2015;308:C176-C188.

54. Frausto RF, Le DJ, Aldave AJ. Transcriptomic analysis of cultured corneal endothelial cells as a validation for their use in cell replacement therapy. Cell Transplant. 2016;25:1159-1176.

55. Wang T, Pahlberg J, Cafaro J, et al. Activation of rod input in a model of retinal degeneration reverses retinal remodeling and induces formation of functional synapses and recovery of visual signaling in the adult retina. J Neurosci. 2019;39:6798-6810.

56. Yang NC, Ho WM, Chen YH, Hu ML. A convenient one-step extraction of cellular ATP using boiling water for the luciferin-luciferase assay of ATP. Anal Biochem. 2002;306:323-327.

57. Swamynathan SK, Davis J, Piatigorsky J. Identification of candidate Klf4 target genes reveals the molecular basis of the diverse regulatory roles of Klf 4 in the mouse cornea. Invest Ophthalmol Vis Sci. 2008;49:3360-3370.

58. Okumura N, Nakamura T, Kay EP, Nakahara M, Kinoshita $\mathrm{S}$, Koizumi N. R-spondin1 regulates cell proliferation of corneal endothelial cells via the Wnt $3 \mathrm{a} / \beta$-catenin pathway. Invest Ophthalmol Vis Sci. 2014;55:6861-6869.

59. Shimizu M, Goto T, Sato A, Shibuya H. WNK4 is an essential effector of anterior formation in FGF signaling. Genes Cells. 2013;18:442-449.

60. Ostojic J, Grozdanic S, Syed NA, et al. Neuroglobin and cytoglobin distribution in the anterior eye segment: a comparative immunohistochemical study. J Histochem Cytochem. 2008;56:863-872.

61. Cheong YK, Ngoh ZX, Peh GS, et al. Identification of cell surface markers glypican -4 and CD200 that differentiate human corneal endothelium from stromal fibroblasts. Invest Ophthalmol Vis Sci. 2013;54:4538-4547.

62. Yildiz E, Bardak H, Gunay M, et al. Novel zinc finger protein gene 469 (ZNF469) variants in advanced keratoconus. Curr Eye Res. 2017;42:1396-1400.

63. Vincent AL, Jordan CA, Cadzow MJ, Merriman TR, McGhee $\mathrm{CN}$. Mutations in the zinc finger protein gene, ZNF469, contribute to the pathogenesis of keratoconus. Invest Ophthalmol Vis Sci. 2014;55:5629-5635.

64. Lechner J, Porter LF, Rice A, et al. Enrichment of pathogenic alleles in the brittle cornea gene, ZNF469, in keratoconus. Hum Mol Genet. 2014;23:5527-5535.

65. Lu Y, Dimasi DP, Hysi PG, et al. Common genetic variants near the Brittle Cornea Syndrome locus ZNF469 influence the blinding disease risk factor central corneal thickness. PLoS Genet. 2010;6:e1000947. 
bioRxiv preprint doi: https://doi.org/10.1101/868281; this version posted August 13,2020 . The copyright holder for this preprint (which was not certified by peer review) is the author/funder. All rights reserved. No reuse allowed without permission.

Energy Shortage in SLC4A11 Deficient CEnC

66. Zhang X, Tseng H. Basonuclin-null mutation impairs homeostasis and wound repair in mouse corneal epithelium. PLoS One. 2007;2:e1087.

67. Chung DD, Frausto RF, Lin BR, Hanser EM, Cohen Z, Aldave AJ. Transcriptomic profiling of posterior polymorphous corneal dystrophy. Invest Ophthalmol Vis Sci. 2017;58:32023214.

68. Ehlers N, Modis L, Moller-Pedersen T. A morphological and functional study of congenital hereditary endothelial dystrophy. Acta Ophthalmol Scand. 1998;76:314-318.

69. Ding WX, Yin XM. Mitophagy: mechanisms, pathophysiological roles, and analysis. Biol Chem. 2012;393:547-564.

70. Xian H, Yang Q, Xiao L, Shen HM, Liou YC. STX17 dynamically regulated by Fis1 induces mitophagy via hierarchical macroautophagic mechanism. Nat Commun. 2019;10: 2059.

71. McLelland GL, Lee SA, McBride HM, Fon EA. Syntaxin-17 delivers PINK1/parkin-dependent mitochondrial vesicles to the endolysosomal system. J Cell Biol. 2016;214:275-291.

72. Nieminen AI, Eskelinen VM, Haikala HM, et al. Mycinduced AMPK-phospho p53 pathway activates Bak to sensitize mitochondrial apoptosis. Proc Natl Acad Sci US A. 2013;110:E1839-E1848.

73. Okoshi R, Ozaki T, Yamamoto H, et al. Activation of AMPactivated protein kinase induces $\mathrm{p} 53$-dependent apoptotic
IOVS | July 2020 | Vol. 61 | No. 8 | Article 39 | 12

cell death in response to energetic stress. J Biol Chem. 2008;283:3979-3987.

74. Jones RG, Plas DR, Kubek S, et al. AMP-activated protein kinase induces a p53-dependent metabolic checkpoint. Mol Cell. 2005;18:283-293.

75. Herzig S, Shaw RJ. AMPK: guardian of metabolism and mitochondrial homeostasis. Nat Rev Mol Cell Biol. 2018;19:121135.

76. Loganathan SK, Casey JR. Corneal dystrophy-causing SLC4A11 mutants: suitability for folding-correction therapy. Hum Mutat. 2014;35:1082-1091.

77. Han SB, Ang HP, Poh R, et al. Mice with a targeted disruption of Slc4a11 model the progressive corneal changes of congenital hereditary endothelial dystrophy. Invest Ophthalmol Vis Sci. 2013;54:6179-6189.

78. Kirkness CM, McCartney A, Rice NS, Garner A, Steele AD. Congenital hereditary corneal oedema of Maumenee: its clinical features, management, and pathology. BrJ Ophthalmol. 1987;71:130-144.

79. Breschi A, Djebali S, Gillis J, et al. Gene-specific patterns of expression variation across organs and species. Genome Biol. 2016;17:151.

80. Breschi A, Gingeras TR, Guigo R. Comparative transcriptomics in human and mouse. Nat Rev Genet. 2017;18:425440 . 